\title{
An Investigation of the Southern Ocean Surface Temperature Variability Using Long-Term Optimum Interpolation SST Data
}

\author{
Megha Maheshwari, Rajkumar Kamaljit Singh, Sandip Rashmikant Oza, and Raj Kumar \\ Space Applications Centre, Indian Space Research Organisation, Ahmedabad 380015, India \\ Correspondence should be addressed to Rajkumar Kamaljit Singh; kamaljit.rajkumar@gmail.com
}

Received 12 June 2013; Accepted 10 July 2013

Academic Editors: S. Focardi, C. Grenz, and M. Lipinski

Copyright ( 2013 Megha Maheshwari et al. This is an open access article distributed under the Creative Commons Attribution License, which permits unrestricted use, distribution, and reproduction in any medium, provided the original work is properly cited.

An attempt is made to understand the long-term variability of SST using NOAA optimum interpolation SST data for the period (1982-2011) in the Southern Ocean. This dataset has been used (i) to study the interannual variability in SST anomaly and (ii) to carry out regression analysis to compute linear trend in the annual averaged Southern Ocean SST. It is observed that summer season exhibits more variability than winter. Moreover, El Nino/La Nina events apparently play a critical role in the variability of Southern Ocean SST. Thus, higher SST anomalies were observed in El Nino years (e.g., 1983), while cooler anomalies were seen during La Nina years (e.g., 1985). In addition, the eastern and western sides of Antarctica experience episodes of warm and cold SST. Western parts of the Southern Ocean experienced higher anomalies during 1992, 1993, and 1994, while the eastern part experienced positive anomalies in 1997, 1998, 2002, and 2003. The paper also highlights the different regions of the Southern Ocean showing statistically significant positive/negative trends in the variability of interannual average SST. However, in general, the Southern Ocean as a whole is showing a weak interannual cooling trend in SST.

\section{Introduction}

Sea surface temperature (SST) plays an important role in oceanic heat content controlling the interactions between ocean and atmosphere [1]. Changes in SST can be considered as one of the most important indicators of climate change. Oceans are huge reservoirs of heat, and the heat release plays a major role in climate both in regional as well as global scale. SST is a one of the parameters directly related to this heat release. Thus, studying the variations of SST over a long period is important in understanding the nature of global climate change.

As observed by many researchers [2-5], the distribution of temperature on the sea surface is apparently zonal in behaviour, with the warmest water near the equator and the colder ones in the polar regions. Deviations from this behaviour are small. However, Deser et al. [6] evaluated the 20th century SST trends using 5 different datasets, and a significant global warming trend was observed, except in some regions like the northwestern Atlantic. They reported the largest warming trends in the midlatitudes.

In the polar regions, surface temperature regulates the growth of sea ice, its melt, and the energy exchange between surface and atmosphere [7]. Comiso [8] evaluated the thermal infrared (TIR) data from the advanced very high resolution radiometer (AVHRR) for the period from 1979 to 1998 ( 20 yr data) to study the trends in surface temperature in the Antarctic region and found a slightly negative trend. The result was found to be consistent with the slightly positive trend in sea ice extent observed by Cavalieri et al. [9]. Using satellite remote sensing data from AVHRR over a period of 24 years from 1982 to 2005 , Lebedev [10] has found a negative trend of SST over the entire Southern Ocean.

Kwok and Comiso [11] studied the relationship between Southern Oscillation and the anomalies of Southern Ocean climatic parameters, namely, sea level pressure, wind, surface air temperature, and sea surface temperature fields and sea ice variables including extent, concentration, motion, and 
surface temperature. These climatic variables were correlated with the Southern Oscillation Index (SOI) for study period spanning 17 years from 1982 to 1998, with strong correlations obtaining around the regions of Bellingshausen, Amundsen, and Ross Seas.

In the polar oceans, sea ice generally forms when the temperature of seawater reaches below $-1.8^{\circ} \mathrm{C}$. Owing to its high albedo, sea ice reflects most of the incoming solar radiation, cooling down the polar environment. Increase in global SST will affect upon the polar environment via the oceanic circulations. This would inhibit the formation of sea ice and would lead to more absorption of the incoming solar radiation, thereby warming up the polar regions (positive albedo-temperature feedback) [12].

Studies show that the thinning of ice shelves and drainage of glacier in Antarctica, could be the result of warming ocean temperature rather than warming air temperature [13]. Thus, SST over the Southern Ocean is a sensitive parameter by which the climate change signals are expected to be recognised $[14,15]$.

Our paper is organized into four sections, with the concluding remarks briefed in Section 4. Section 2 describes the data and the overall methodology of this study.

In Section 3, we present our findings on the interannual variability in SST anomaly over the Southern Ocean (Section 3.1) and the warming/cooling trends (Section 3.2) observed in interannual average surface temperature.

Some significant features were observed in four sectors, namely, the Weddell Sea-Ross Sea sectors and the AmundsenBellingshausen Seas (ABS)-Indian Ocean sectors, and this is discussed in detail in Section 3.3. These sectors are important because of various reasons. The Weddell and Ross Seas are regarded as the regions of key sources of cold and dense bottom water that influences global ocean circulation [16]. Ross Sea and ABS sectors are influenced by El Niño-Southern Oscillation (ENSO) episodes [11]. In addition, the ice cover in the Bellingshausen Sea is the habitat for a wide variety of marine life and is crucial to their survival.

Our study here may be regarded as an extension to similar other studies by many researchers mentioned earlier in this field, and in that, we have extended the period of study to the recent times, which will therefore incorporate signals of recent climate change.

\section{Data and Methodology}

Oceanographic changes in the SST for different regions of Southern Ocean were observed with the help of NOAA optimum interpolation (OISST Version 2) [17] (henceforth OI.v2) for the period from January 1982 to October 2011. The OI.v2 dataset contains monthly SST fields derived by a linear interpolation of the weekly OI fields to produce daily fields then averaging the appropriate daily values within a month to produce monthly averages. The analysis uses insitu and satellite SSTs plus SSTs simulated by sea ice cover over the marginal ice zone (MIZ) where both in situ as well as satellite observations is sparse due to navigation hazards and cloud cover, respectively. The OI.v2 analysis has a modest improvement over the version 1 [18] in the bias correction because of the addition of more in situ data. The SST dataset is on a $1^{\circ} \times 1^{\circ}$ grid resolution. The first grid box is centered on $0.5^{\circ} \mathrm{E}, 89.5^{\circ} \mathrm{S}$. The points move eastward to $359.5^{\circ} \mathrm{E}$ and northward to $89.5^{\circ} \mathrm{N}$. These datasets are obtained from NOAA/OAR/ESRL PSD, Boulder, Colorado, USA, (website: http://www.esrl.noaa.gov/psd/) and are interpolated into the polar stereographic projection using cubic convolution resampling technique [19].

For distinguishing El Niño and La Niño events, we use the Oceanic Nino Index (ONI), a standard index used by the Climate Prediction Center-NOAA [20].

In this paper, we first study the inter-annual variability in surface temperature over the entire Southern Ocean by comparing among the annual anomaly maps generated as a difference between each yearly SST and the long-term (1982-2010) average SST. We computed annual (Jan.-Dec.) averages in order to remove seasonal variations in the surface temperature fields. We then perform a regression analysis to compute the inter-annual trend in the Antarctic and the regions with statistically significant trends are marked with contours.

A discussion on the decadal variations of SST during three distinct decades, namely, 1982-1991, 1992-2001, and 2002-2011, is presented in this paper. For this, the decadal monthly anomalies were generated by first creating the decadal means and then removing the monthly climatology from each decade for the same month.

The Southern Ocean is subdivided into different sectors as shown in Figure 1(a), following Markus and Cavalieri [21]. Figures 1(a) and 1(b), respectively, show the contours of longterm (1982-2011) austral summer (ONDJFM) and winter (AMJJAS) seasonal mean SSTs, spaced at $2.5^{\circ} \mathrm{C}$ intervals. Superimposed upon these seasonal SST contours are the standard deviations (computed over the entire season) of SST anomalies given in shades of different colours. Some key features of this figure are (i) near-zonally symmetric isotherms, decreasing toward the pole and (ii) more variability during summer season compared to the winter.

\section{Results and Discussion}

3.1. Interannual Variability in Surface Temperature Anomalies. Figure 2 shows the inter-annual variability of the Antarctic surface temperature anomalies for the period from 1982 to 2010. From this time sequence images, it appears that East Antarctica, in general, and the Western Pacific Ocean (WPO) sector, in specific, are substantially cooler than any other sectors in the year 1982, while during 1999-2000, the Ross Sea sector appears cooler. However, the subsequent year, 1983, shows a relatively higher anomaly in the AmundsenBellingshausen Seas (ABS) sector as well as the Indian Ocean (IO) and the adjacent regions of the WPO. The ONI values for 1982 Aug-Sep-Oct mean were of the order of $+1.5^{\circ} \mathrm{C}$ (a threshold for stronger El Niño events) and wherefrom it continued to be in excess of this threshold till Feb-Mar-Apr mean of 1983. Therefore, the observed higher anomaly in 1983 in our study could be a possible effect of this. 


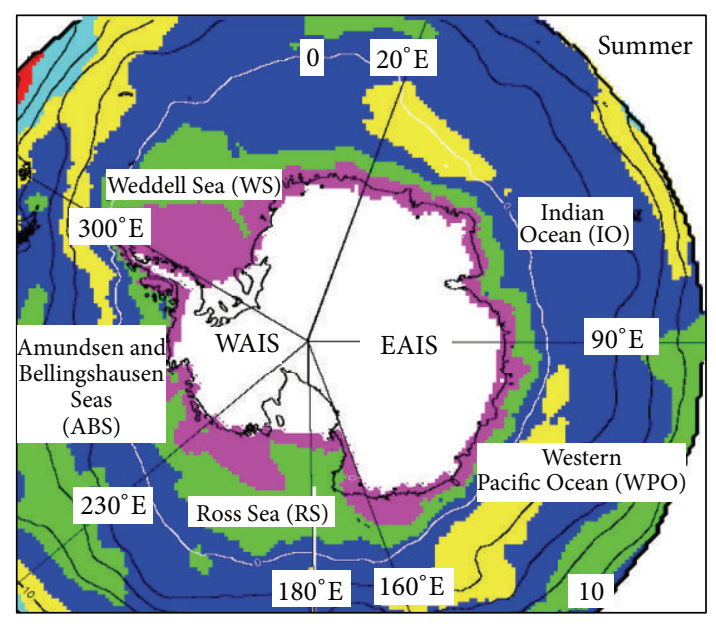

(a)
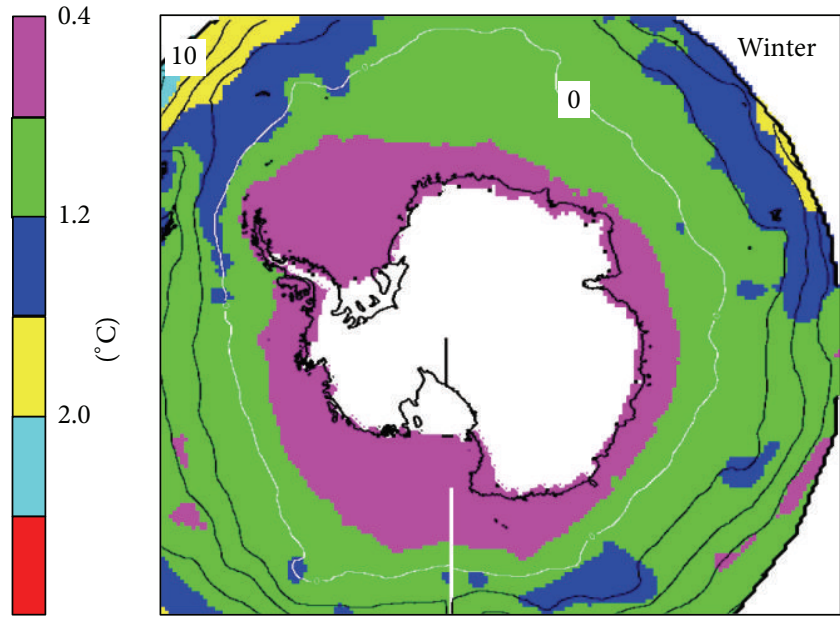

(b)

FIGURE 1: Long-term mean SSTs (contours) and standard deviations of SST anomalies (shading) for the (a) austral summer (ONDJFM) and (b) winter (AMJJAS) season. Contour interval is $2.5^{\circ} \mathrm{C} ; 0^{\circ} \mathrm{C}$ and $10^{\circ} \mathrm{C}$ isotherms are marked. Also, the different sectors of Antarctica are shown relevant to this present study. EAIS and WAIS represent East Antarctic Ice Sheet and West Antarctic Ice Sheet, respectively.

West Antarctica experienced higher anomalies during $1992,1993,1994,1995$, and so forth, whereas in years like 1997, 1998, 2002, 2003, and so forth, East Antarctica experienced positive anomalies. Comiso [8] has also found the years 19941996 to be warmer. However, it may be noted here that he had used only the July month anomalies for the period from 1979 to 1998; while in our case, we have used annual average anomalies. The year 1992 experienced moderately strong El Niño event and thus the higher surface temperature anomaly observed in our study, while 1994-95 had a weak El Niño. The year 1997, showing an overall warming in almost all the sectors of Southern Ocean, was a strong El Niño year. The colder anomalies observed in our study could possibly be explained in terms of the La Niña event. Hence, years like 1999 and 2000 having strong La Niña events show colder anomalies in the eastern as well as the western Antarctic waters, for example, the WPO and the ABS sectors.

Time series plot of temperature anomalies in ${ }^{\circ} \mathrm{C}$ for the Southern Ocean (here taken to be the oceanic regions beyond $\sim 45^{\circ} \mathrm{S}$ up to the Antarctic continent boundaries) is given in Figure 3. The mean anomaly (black), maximum values (red), minimum (blue), and standard deviations (dashed) are plotted in it. In the plot, each mean value represents the average temperature anomaly over the entire Southern Ocean for a particular year; minimum (maximum) is a value at a particular pixel with the lowest (highest) temperature; standard deviations represent the fluctuations around the mean over the entire period of study. The statistics shown are for the linear regression over the yearly mean SST.

The highest temperature $\left(0.12 \pm 0.21^{\circ} \mathrm{C}\right)$ anomaly over the entire Southern Ocean is observed in the year 1997, while 2008 with an anomaly temperature of $-0.12 \pm 0.21^{\circ} \mathrm{C}$ represents the coldest year in our study. We performed a linear regression over the annual-averaged temperature anomaly data, and we found that over the entire region, there is a weak negative trend. However, at $95 \%$ confidence, the negative trend is not statistically significant as suggested by the statistical $P$ value ( $>0.05)$. We will discuss about the trend analysis on a grid-wise scale in the following subsection.

\subsection{Trend Analysis of Interannual Average Temperatures. A} grid-wise trend analysis is carried out using linear regression in order to see if there is any significant trend in the variations of the inter-annual average surface temperatures. A trend map is generated as shown in Figure 4. In the figure, regions with statistically significant trends are marked by a dashed contour.

Oza et al. [22] used the entire life span (1999-2009) data of QuikSCAT to study the inter-annual variations in the summer and spring sea ice extent in the Arctic as well as the Antarctic. They found a significant positive sea ice trend in the IO sector. This can be explained by the observed cooling trend of surface temperature visible in the IO sector.

The WPO sector close to the coast shows a cooling trend. However, farther away from the coast $\left(<60^{\circ} \mathrm{S}\right.$ toward the equator), a significant warming trend is observed. During summer season, this region is almost entirely ice-free.

Majority of the Ross Sea sector is showing a cooling trend. However, there is a small region near the Ross shelf showing both slight warming and cooling trend. Moving toward $60^{\circ} \mathrm{S}$, a more prominent cooling trend is observed.

The ABS sector is showing statistically significant warming trend in consistency with the findings of decreasing sea ice trend by Oza et al. [22, 23]. Likewise, here too, around $60^{\circ} \mathrm{S}$, the SST anomaly trend is more toward cooling than warming. In the Weddell Sea sector (WS), majority of the region is showing a significant cooling trend.

In addition to this, we also present here in Figure 5 a colour-coded map showing the difference between the annual average surface temperature in 2010 and 1982, the end and beginning of our analysis period. This image will 


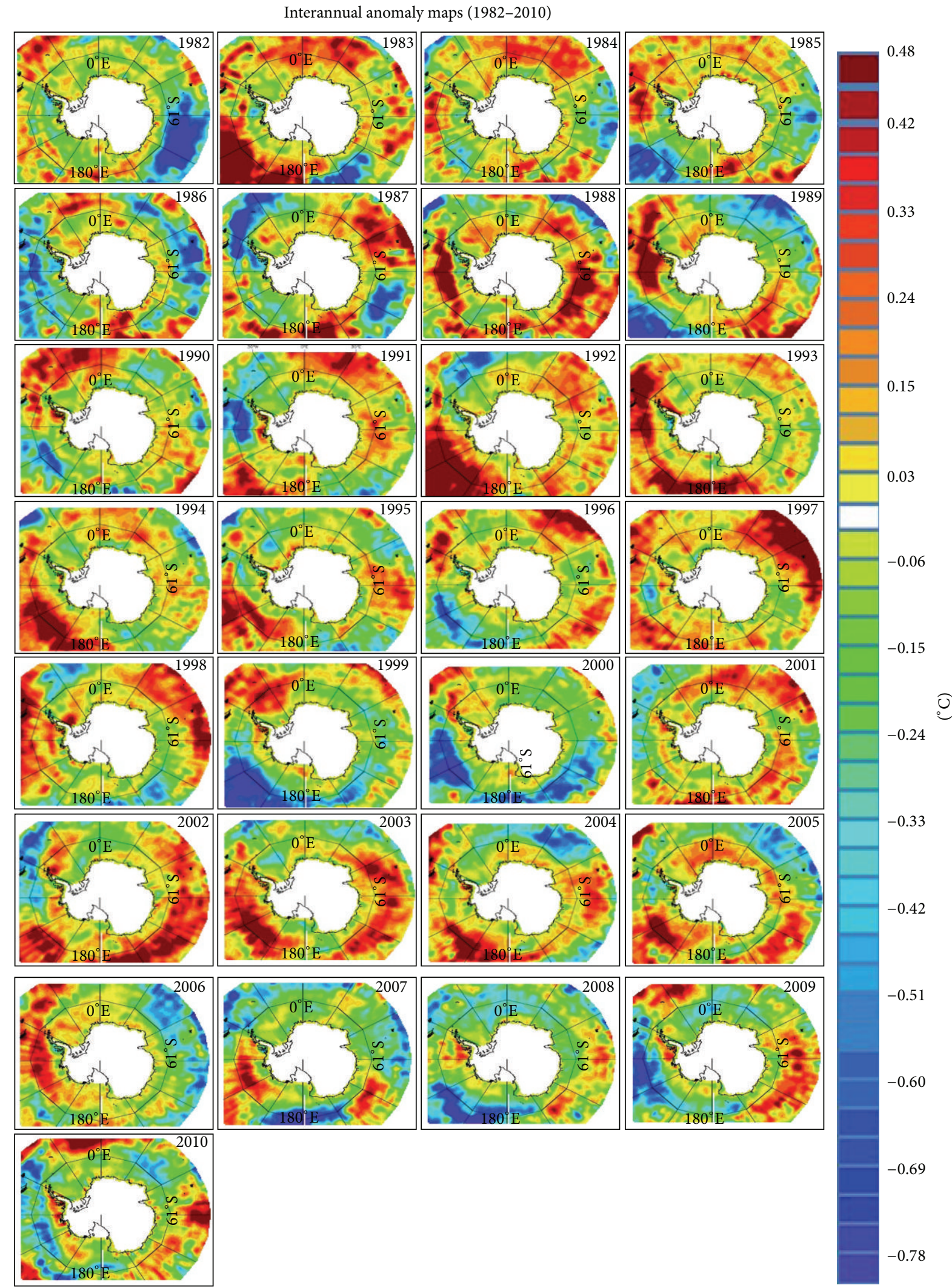

Figure 2: Antarctic annual (January-December) anomaly maps of surface temperatures for the period from 1982 to 2010. Anomalies are computed by subtracting the long-term average from the yearly average. 


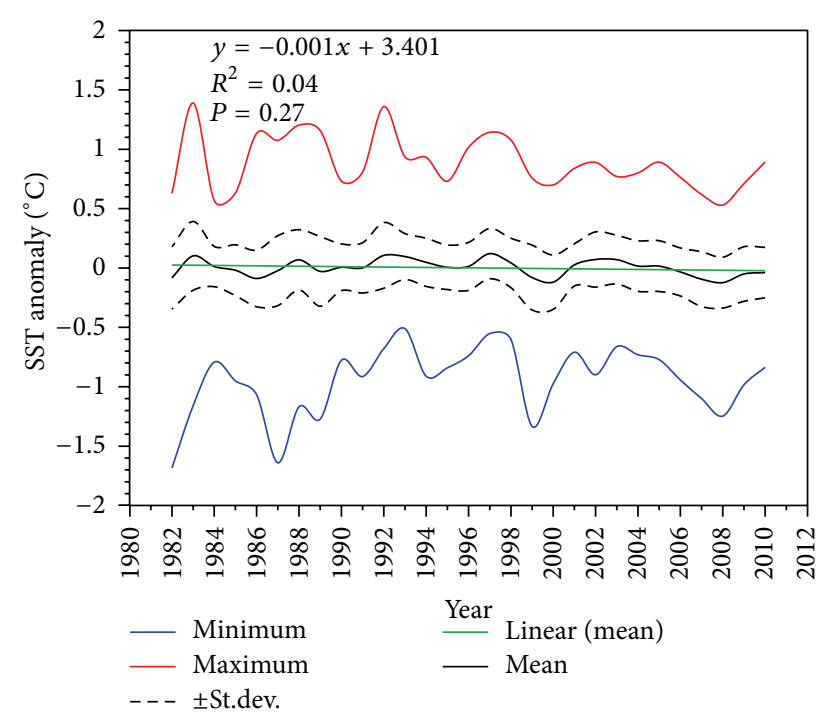

FIGURE 3: Time series showing the variation of Southern Ocean surface temperature anomalies (in ${ }^{\circ} \mathrm{C}$ ). Black line shows the mean anomaly, red line gives the maximum values, blue line, minimum, and the dashed lines represent \pm sigma. Here, mean represents the average temperature anomaly over the entire region; minimum (maximum) is a value at a particular pixel with the lowest (highest) temperature; standard deviation represents the fluctuations around the mean over the entire period of study. A linear trend (green straight line) is also shown, with the regression statistics given at the top left corner.

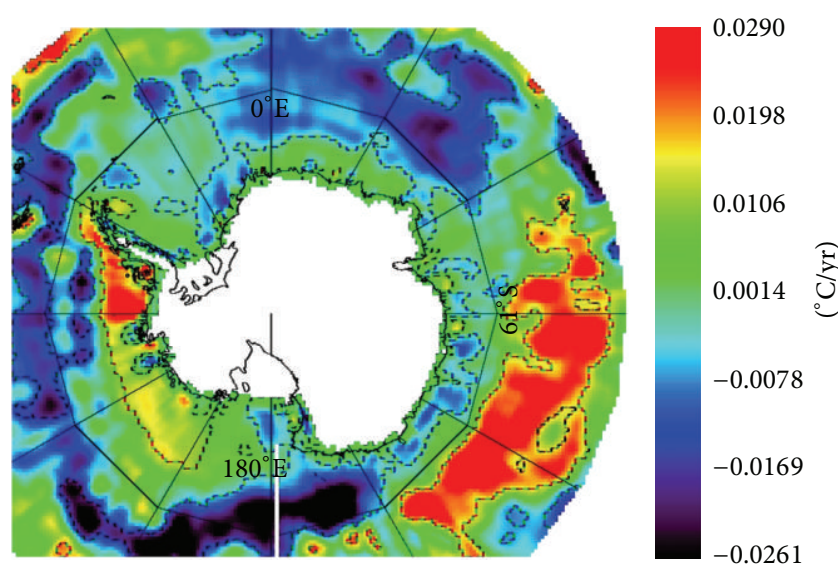

FIGURE 4: Trends in Southern Ocean surface temperature anomalies for the period from 1982 to 2010. Regions with statistically significant trends are marked by the dashed contours.

help in visualising the magnitude of change in the surface temperatures during this period of study. The warming and cooling trends observed in the previous figure, Figure 4, are also, in general, visible in this difference map, Figure 5. However, the strong warming trend in the ABS as observed in Figure 4 is not widespread as shown in Figure 5. Another point of difference is at the South Atlantic Ocean at around $15^{\circ}-0^{\circ} \mathrm{E}$ and $53^{\circ} \mathrm{S}$ where a strong warming is observed.

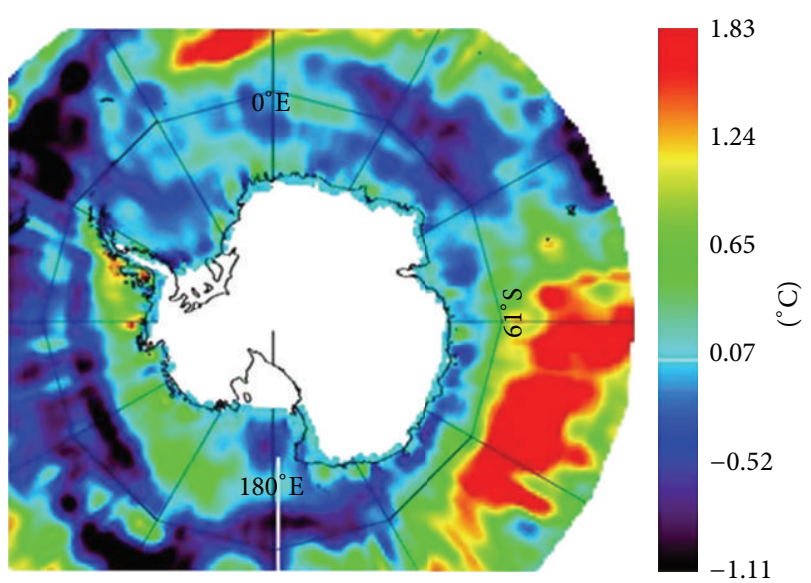

FIGURE 5: Difference map between annual average surface temperature of 2010 and 1982.

From both these images, a very important observation can be made; that is, the part of the Southern Ocean in the East Antarctic sector is experiencing a significant warming while the West Antarctic sector, a more significant cooling, in general. However, as a whole, the area experiencing cooling over the entire Southern Ocean is larger than that experiencing warming.

3.3. Regional Assessment of the Variations in Decadal SST Anomalies. In our analysis, it was found that four different sectors in the Antarctic (the ABS-Ross Sea and the Weddell Sea-IO sectors) were showing some distinct patterns of SST variation during the austral summer month of February. It appears that there exists a linkage between the temperature patterns in one sector with that in another sector. For the entire study period from 1982 to 2011, a negative correlation of $\sim-0.43(P=0.01)$ is observed in the ABS-Ross sector pair and a statistically weak negative correlation of $\sim-0.27$ $(P=0.15)$ at the Weddell-IO sector. We discuss here the patterns of SST variations in three discrete decades, namely, 1982-91, 1992-2001, and 2002-11.

3.3.1. Amundsen-Bellingshausen Sea-Ross Sea Sector Pair. In the Bellingshausen Sea, the February decadal mean anomaly for the period (1982-91) shows a large cold anomaly near the George VI Sound Ice Shelf (Figure 6(a)). This was around $0.6^{\circ} \mathrm{C}$ colder than the decadal average value for the period $1982-91$. However, a positive anomaly of around $0.5^{\circ} \mathrm{C}$ was observed in the Drake Passage. The result so obtained in the western part of the Antarctic Peninsula is consistent with those reported by Meredith and King [24] using hydrographic data of the region west to the Western Antarctic Peninsula.

Apparently, the cold surface temperature episode in the ABS sector during 1982-91 gradually gave way to a warmer episode of 2002-11. The temperature anomaly in 2002-11 was $\sim 0.4^{\circ} \mathrm{C}$. It may, however, be noted that in 2002-11, the Drake Passage experienced a cooler anomaly $\left(\sim 0.3^{\circ} \mathrm{C}\right.$ lesser than the decadal average around this region). 
1982-1991

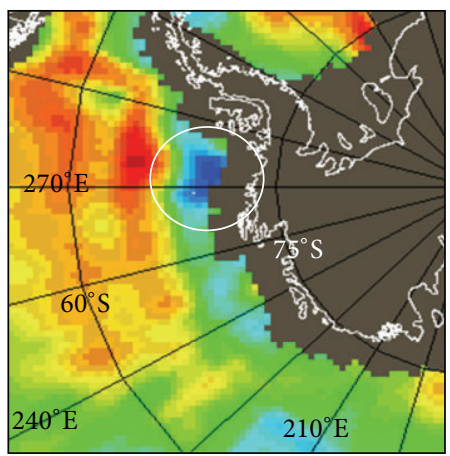

1992-2001

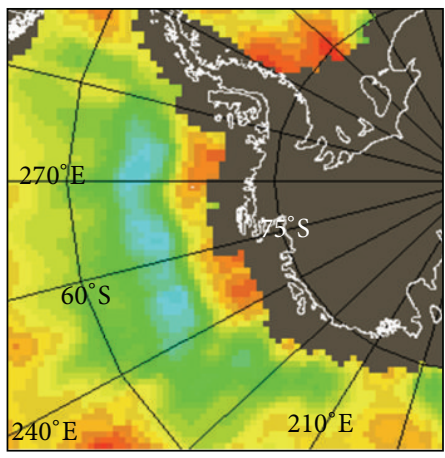

$\left({ }^{\circ} \mathrm{C}\right)$

\begin{tabular}{llllllllll}
-0.66 & -0.51 & -0.36 & -0.21 & -0.06 & 0.09 & 0.24 & 0.39 & 0.54 & \\
\hline
\end{tabular}

(a)
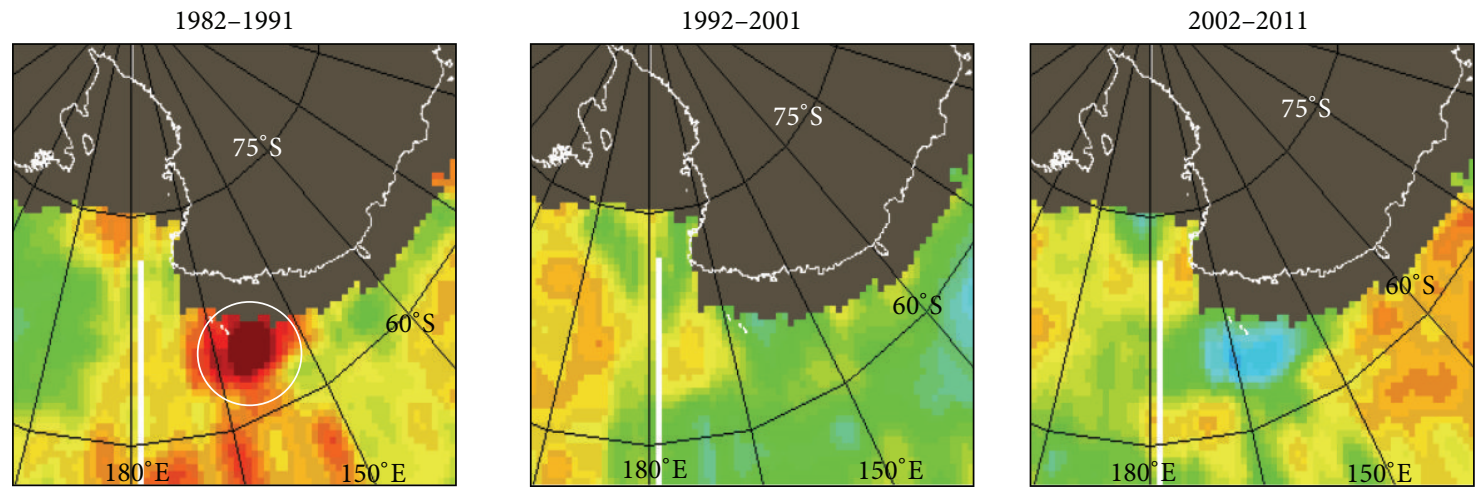

$\left({ }^{\circ} \mathrm{C}\right)$

\begin{tabular}{llllllllll}
-0.66 & -0.51 & -0.36 & -0.21 & -0.06 & 0.09 & 0.24 & 0.39 & 0.54 \\
\hline
\end{tabular}

(b)

FIGURE 6: Color coded maps for the month of February (austral summer) representing decadal SST anomalies for three successive decades: 1982-1991, 1992-2001 and 2002-2011. (a) shows the variations of SST anomalies over Amundsen-Bellingshausen Seas sector; anomaly variations over Ross Sea sector are shown in (b). Negative anomaly in the ABS sector during the period 1982-91 is visible which progressively becomes positive in 2002-11. However, Ross Sea shows intense warmer SST during 1982-91 and slowly changes to colder SST during 2002-11. Gray color represents the continent. Regions of study are marked by white circles.

The situation in the Ross Sea sector (Figure 6(b)) shows a complete reversal of the anomaly pattern as observed in the ABS sector. Here, warmer temperature was observed for the decade 1982-91 with a temperature anomaly of $\sim 0.6^{\circ} \mathrm{C}$ which changed to a colder temperature in 2002-11 with an anomaly of $\sim-0.4^{\circ} \mathrm{C}$. El Niño events in the years such as 1983, 1987, 1992, and 1998 might have significantly contributed to the anomaly patterns so observed in these sectors.

3.3.2. Weddell Sea-Indian Ocean Sector Pair. An almost similar behaviour is observed in the Weddell Sea-Indian Ocean sectors (Figures $7(\mathrm{a})$ and $7(\mathrm{~b})$ ). Even though the surface temperature cooled down from $0.5^{\circ}$ to $-0.3^{\circ} \mathrm{C}$ in the three successive decades, the change in the Weddell Sea is not that gradual as observed in the Ross sea sector. As evident, the two decades, 1982-92 and 1992-2001, have almost comparable positive anomalies around the Weddell Sea region, while the cooling became apparent only during the last decade 2002-11. In the Indian Ocean sector, a trivial warming was observed near the Amery shelf basin (left of the ellipse in Figure 7(b)) in the period 1982-91 which moved toward the northern side and amplified at around $45^{\circ} \mathrm{S}$ in $2002-11$. In this region, the surface temperature deviates from the mean by as much as $0.4^{\circ} \mathrm{C}$ for the period of the three decades $1982-91$ to $2002-11$.

In order to gain more insight about this behaviour in the temporal domain, a 30-year trend analysis of SST anomaly has been carried out for the month of February. It has been 
1982-1991

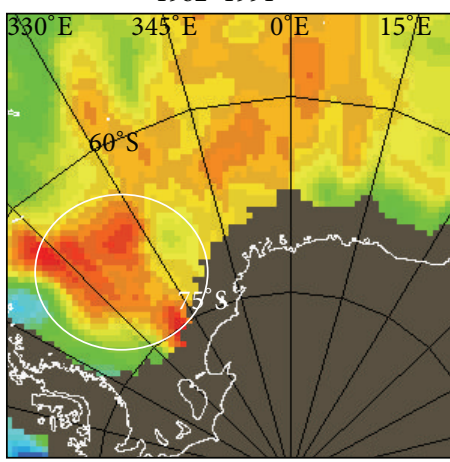

$-0.66$
1992-2001

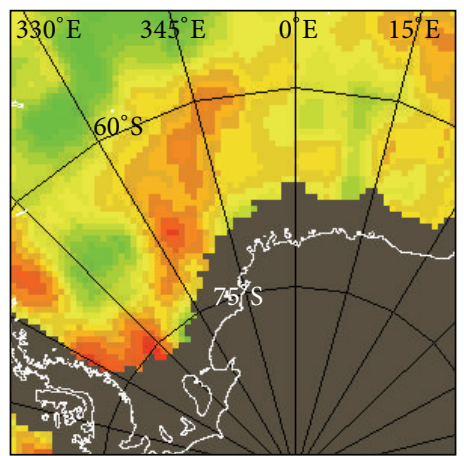

$\left({ }^{\circ} \mathrm{C}\right)$
2002-2011

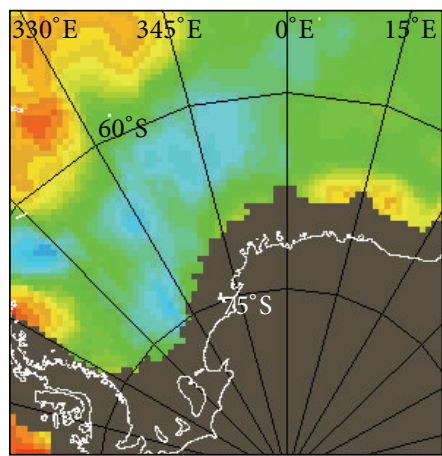

0.24

0.54

(a)
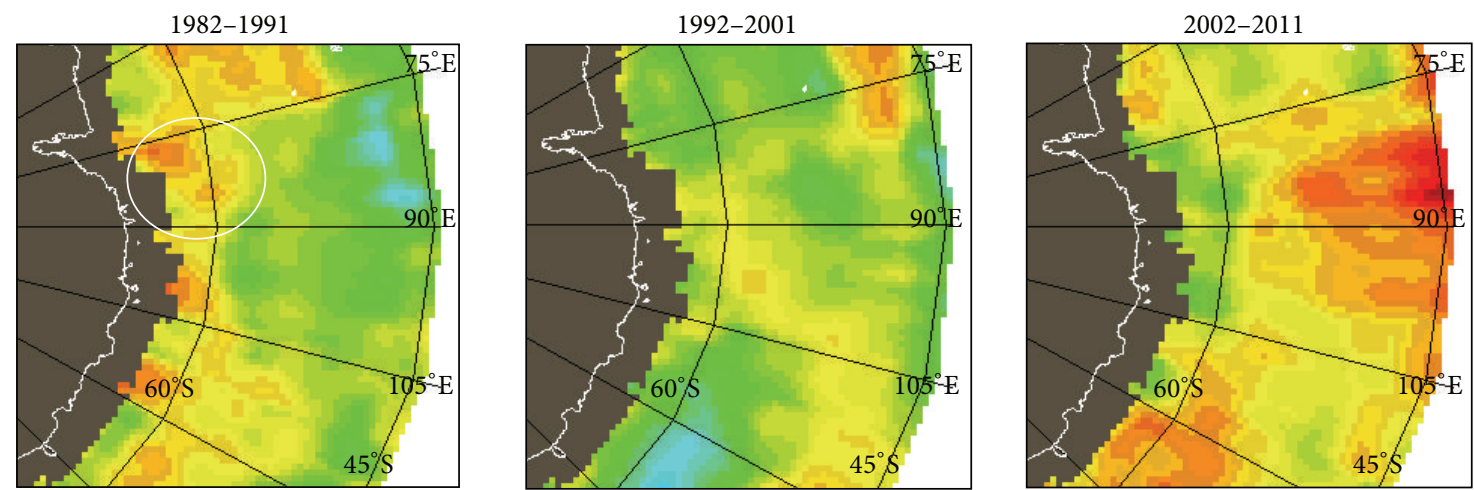

$\left({ }^{\circ} \mathrm{C}\right)$

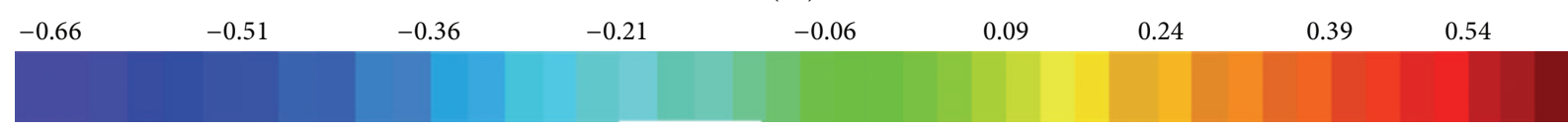

(b)

FIGURE 7: As in Figure 6, but for the (a) Weddell Sea and (b) Indian Ocean sectors of Southern Ocean. Temperature anomaly in Weddell Sea sector has decreased by $0.2^{\circ} \mathrm{C}$ from the period 1982-91 to 2002-11. However, in Indian Ocean sector (around $90^{\circ} \mathrm{E}$ ), the surface temperature of ocean deviates up to $0.4^{\circ} \mathrm{C}$ from the average from 1982-91 to 2002-11.

found that the time sequence of SST anomalies shows larger year-to-year variability for all the four regions (Figure 8). The study reveals that the ABS sector has a positive trend at a rate of $0.02 \pm 0.01^{\circ} \mathrm{C} / \mathrm{yr}$. The temperature anomaly varies from the lowest of $-0.67^{\circ} \mathrm{C}$ in 1986 to the highest of $0.70^{\circ} \mathrm{C}$ in 2003 . However, in the adjacent seas: Ross and Weddell seas cooling trends of $-0.04 \pm 0.01^{\circ} \mathrm{C} / \mathrm{yr}$ and $-0.02 \pm 0.01^{\circ} \mathrm{C} / \mathrm{yr}$, respectively, were observed. In case of Indian Ocean sector, 2011 was the warmest year $\left(0.68^{\circ} \mathrm{C}\right.$ more than the average). There is a steep increase in the surface temperature from 2005 to 2011, an increase of about $0.97^{\circ} \mathrm{C}$. Overall, a positive trend has been observed in the Indian Ocean sector, which is amplifying at a rate of $0.02 \pm 0.01^{\circ} \mathrm{C} /$ year.

The comparative investigation provided an interesting result that during the 30-year time period both the lowest as well the highest temperature anomalies occurred only over the Ross Sea sector among all the four with $-0.81^{\circ} \mathrm{C}$ in 1995 and $1.08^{\circ} \mathrm{C}$ in 1984 , respectively.

\section{Conclusion}

In this study, the variations of NOAA analysed sea surface temperatures over the Southern Ocean have been investigated for the period from 1982 to 2011. Inter-annual variability of the Antarctic surface temperature anomalies for the period from 1982 to 2010 is studied. The Western Pacific Ocean (WPO) sector experienced a substantially colder surface temperature than any other sectors in 1982. As expected, the El Niño events have impacts on the Antarctic waters, and in 1983, a higher surface temperature over the Southern Ocean has been reported. 


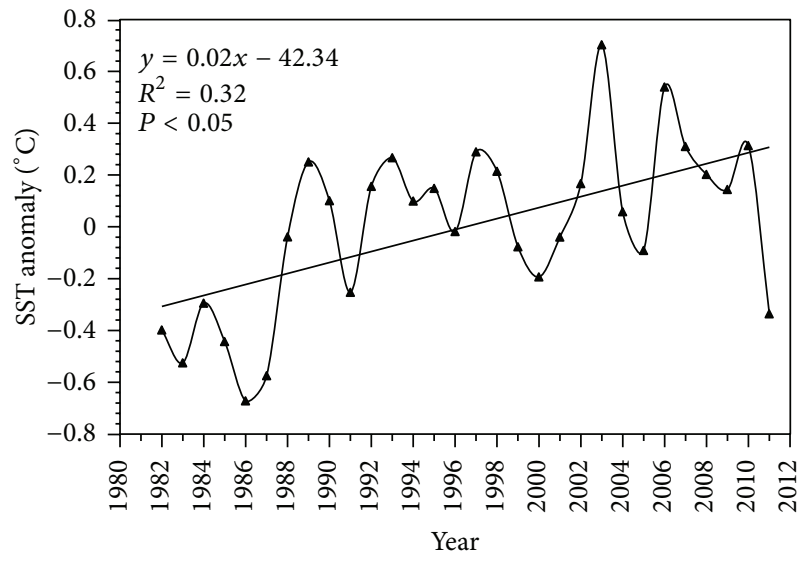

(a)

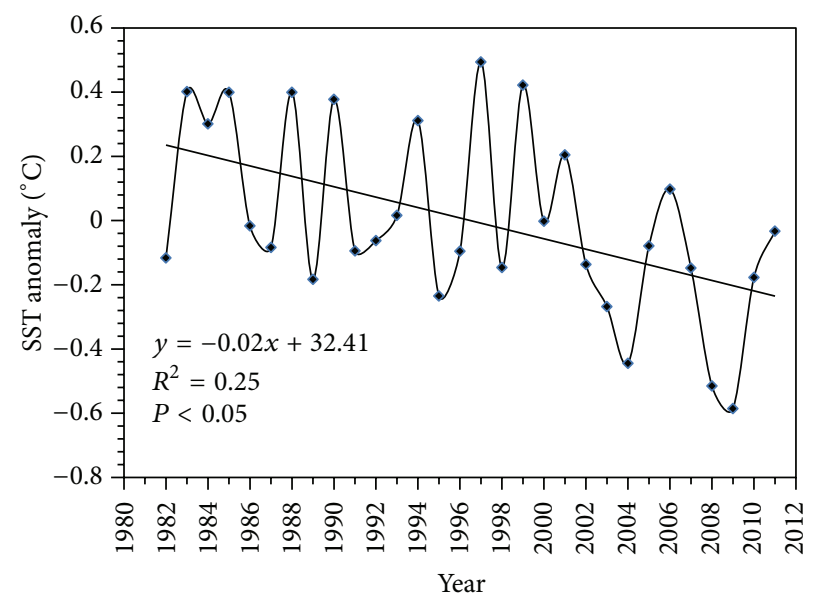

(c)

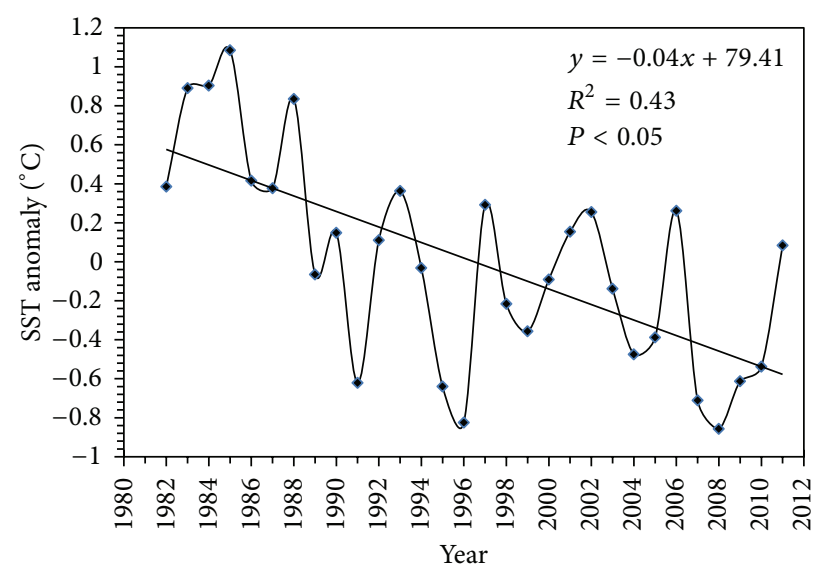

(b)

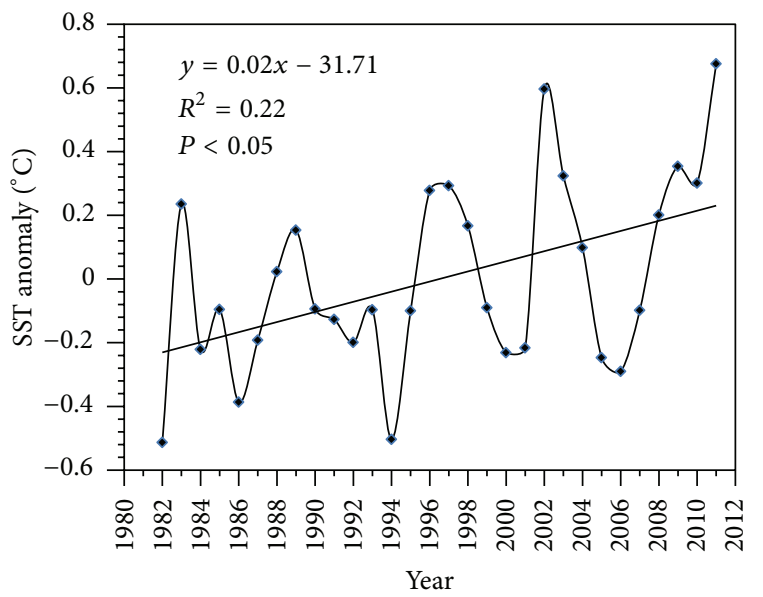

(d)

FiguRE 8: A 30-year trend analysis of surface temperature anomalies over four different sectors of the Southern Ocean summer month of February over four different sectors of (a) Amundsen-Bellingshausen Seas, (b) Ross Sea, (c) Weddell Sea, and (d) Indian Ocean sectors. ABS and Indian Ocean sectors are showing positive trends at per year rate of $0.02 \pm 0.01^{\circ} \mathrm{C}$. However, negative trends of $-0.04 \pm 0.01^{\circ} \mathrm{C} / \mathrm{yr}$ and $-0.02 \pm 0.01^{\circ} \mathrm{C} / \mathrm{yr}$ have been computed over Ross Sea and Weddell Sea sectors, respectively.

East and West Antarctic waters experienced different episodes of warming and cooling events. Thus, West Antarctica experienced higher anomalies during 1992, 1993, 1994, 1995, and so forth, whereas in years like 1997, 1998, 2002 and 2003, East Antarctic experienced positive anomalies.

From the time series analysis of the variation of Southern Ocean surface temperature anomalies, a slightly negative (i.e., cooling) trend in average temperature anomaly over the entire region is obtained. However, this trend is very weak and found to be statistically insignificant. However, on a regional scale, there are regions showing statistically significant trends in warming/cooling surface temperatures. Thus, regions like Amundsen-Bellingshausen Seas sector are showing statistically significant warming trend, while the Western Pacific Ocean sector close to the continental coast is showing a cooling trend, and the far off regions over the ocean are, however, giving a warming trend.

We have also studied in this paper the variation of decadal anomalies for the month of February (austral summer) for 4 different sectors in Antarctica. It is found that the warming trend is dominant over ABS and Indian Ocean sectors, while the Ross Sea and Weddell Sea are experiencing a cooling trend.

One of the very important findings of this analysis is the steep rise in summer surface temperature observed in the Indian Ocean from 2005 to 2011. If this rise continues for more years to come, it would have an adverse effect on the thickness of Amery ice shelf [13].

There are other significant cryospheric impacts of these findings. Majority of the glaciers in the Antarctic region are retreating at an accelerating rate. It is found that the melt rate of ice shelves is directly related to the surface temperature of the ocean [25]. Therefore, our study on the surface temperature variability and the findings, thereof, of a very strong surface warming over some sectors of the Antarctic Ocean would have significant implications on the future of the ice shelves and global climate change.

A prolonged change in the ocean temperature would change the sea ice cover, and this will affect the regional-scale ecosystem. As pointed out by Jacobs and Comiso [26], the 
exact cause of SST variations is not yet well know; however, these changes in surface temperature of oceans are linked to a larger scale climate phenomena, which needs to be addressed in more elaborate ways.

\section{Acknowledgments}

The authors are thankful to Shri A. S. Kiran Kumar, Director of SAC-ISRO, for his constant encouragement and guidance to carry out the activities in the field of polar science. The valuable comments given by Dr. J. S. Parihar, Dr. P. K. Pal, Dr. Abhijit Sarkar, and Dr. N. K. Vyas are also acknowledged. NOAA analysed SST data (OISST Version 2) are obtained from NOAA/OAR/ESRL PSD, Boulder, Colorado, USA (website: http://www.esrl.noaa.gov/psd/) and are acknowledged here.

\section{References}

[1] R. W. Reynolds, T. M. Smith, C. Liu, D. B. Chelton, K. S. Casey, and M. G. Schlax, "Daily high-resolution-blended analyses for sea surface temperature," Journal of Climate, vol. 20, no. 22, pp. 5473-5496, 2007.

[2] P. K. Rao, W. L. Smith, and R. Koffler, "Global sea-surface temperature distribution determined from and environmental satellite," Monthly Weather Review, vol. 100, no. 1, pp. 10-14, 1971.

[3] G. W. Paltridge, "Latitudinal variation in the change of sea surface temperature from 1880 to 1977," Monthly Weather Review, vol. 112, no. 5, pp. 1093-1095, 1984.

[4] ADEOS Earth View, "Global Sea Surface Temperature Distribution. Japan Aerospace Exploration Agency, Japan," 1999, http://suzaku.eorc.jaxa.jp/GLI2/adeos/Earth_View/eng/adeos08e.pdf.

[5] NASA Science, “Temperature," National Aeronautics and Space Agency, USA, 2012, http://science.nasa.gov/earth-science/ oceanography/physical-ocean/temperature/.

[6] C. Deser, A. S. Phillips, and M. A. Alexander, "Twentieth century tropical sea surface temperatures revisited," Geophysical Research Letters, vol. 37, no. 10, 2010.

[7] J. R. Key, J. B. Collins, C. Fowler, and R. S. Stone, "Highlatitude surface temperature estimates from thermal satellite data," Remote Sensing of Environment, vol. 61, no. 2, pp. 302-309, 1997.

[8] J. C. Comiso, "Variability and trends in Antarctic surface temperatures from In Situ and satellite infrared measurements," Journal of Climate, vol. 13, no. 10, pp. 1674-1696, 2000.

[9] D. J. Cavalieri, P. Gloersen, C. L. Parkinson, J. C. Comiso, and H. J. Zwally, "Observed hemispheric asymmetry in global sea ice changes," Science, vol. 278, no. 5340, pp. 1104-1106, 1997.

[10] S. A. Lebedev, "Inter-annual trends in the southern ocean sea surface temperature and sea level from remote sensing data," Russian Journal of Earth Sciences, vol. 9, Article ID ES3003, 2007.

[11] R. Kwok and J. C. Comiso, "Southern Ocean climate and sea ice anomalies associated with the Southern Oscillation," Journal of Climate, vol. 15, no. 5, pp. 487-501, 2002.

[12] J. A. Curry, J. L. Schramm, and E. E. Ebert, "Sea ice-albedo climate feedback mechanism," Journal of Climate, vol. 8, no. 2, pp. 240-247, 1995.
[13] E. Rignot, G. Casassa, P. Gogineni, W. Krabill, A. Rivera, and R. Thomas, "Accelerated ice discharge from the Antarctic Peninsula following the collapse of Larsen B ice shelf," Geophysical Research Letters, vol. 31, no. 18, 2004.

[14] A. Mitra, I. M. L. Das, M. K. Dash, S. M. Bhandari, and N. K. Vyas, "Impact of ice-albedo feedback on hemispheric scale sea-ice melting rates in the antarctic using multi-frequency scanning microwave radiometer data," Current Science, vol. 94, no. 8, pp. 1044-1048, 2008.

[15] M. I. Budyko, "Polar ice and climate," in Proceedings of the Symposium on the Arctic Heat Budget and Atmospheric Circulation. RM, 5233-NSF, J. O. Fletcher, Ed., pp. 3-32, Rand Corporation, Santa Monica, Calif, USA, 1966.

[16] G. Budillon, G. Fusco, and G. Spezie, "A study of surface heat fluxes in the Ross Sea (Antarctica)," Antarctic Science, vol. 12, no. 2, pp. 243-254, 2000.

[17] R. W. Reynolds, N. A. Rayner, T. M. Smith, D. C. Stokes, and W. Wang, "An improved in situ and satellite SST analysis for climate," Journal of Climate, vol. 15, no. 13, pp. 1609-1625, 2002.

[18] R. W. Reynolds and T. M. Smith, "Improved global sea surface temperature analyses using optimum interpolation," Journal of Climate, vol. 7, no. 6, pp. 929-948, 1994.

[19] J. A. Richards and X. Jia, Remote Sensing Digital Image Analysis, Springer, Berlin, Germany, 1999.

[20] Climate Prediction Center-NOAA, "Cold \& Warm Episodes by Season. NOAA/ National Weather Service, Center for Weather and Climate Prediction, Climate Prediction Center," 2012, http://www.cpc.ncep.noaa.gov/products/analysis_monitoring/ ensostuff/ensoyears.shtml.

[21] T. Markus and D. J. Cavalieri, "Interannual and regional variability of Southern Ocean snow on sea ice," Annals of Glaciology, vol. 44, pp. 53-57, 2006.

[22] S. R. Oza, R. K. K. Singh, A. Srivastava et al., "Inter-annual variations observed in spring and summer antarctic sea ice extent in recent decade," Mausam, vol. 62, pp. 633-640, 2011.

[23] S. R. Oza, R. K. K. Singh, N. K. Vyas, and A. Sarkar, "Recent trends of arctic and antarctic summer sea-ice cover observed from space-borne scatterometer," Journal of the Indian Society of Remote Sensing, vol. 38, no. 4, pp. 611-616, 2010.

[24] M. P. Meredith and J. C. King, "Rapid climate change in the ocean west of the antarctic peninsula during the second half of the 20th century," Geophysical Research Letters, vol. 32, 2005.

[25] A. Shepherd, D. Wingham, and E. Rignot, "Warm ocean is eroding west antarctic ice sheet," Geophysical Research Letters, vol. 31, 2004.

[26] S. S. Jacobs and J. C. Comiso, "Climate variability in the Amundsen and Bellingshausen Seas," Journal of Climate, vol. 10, no. 4, pp. 697-709, 1997. 

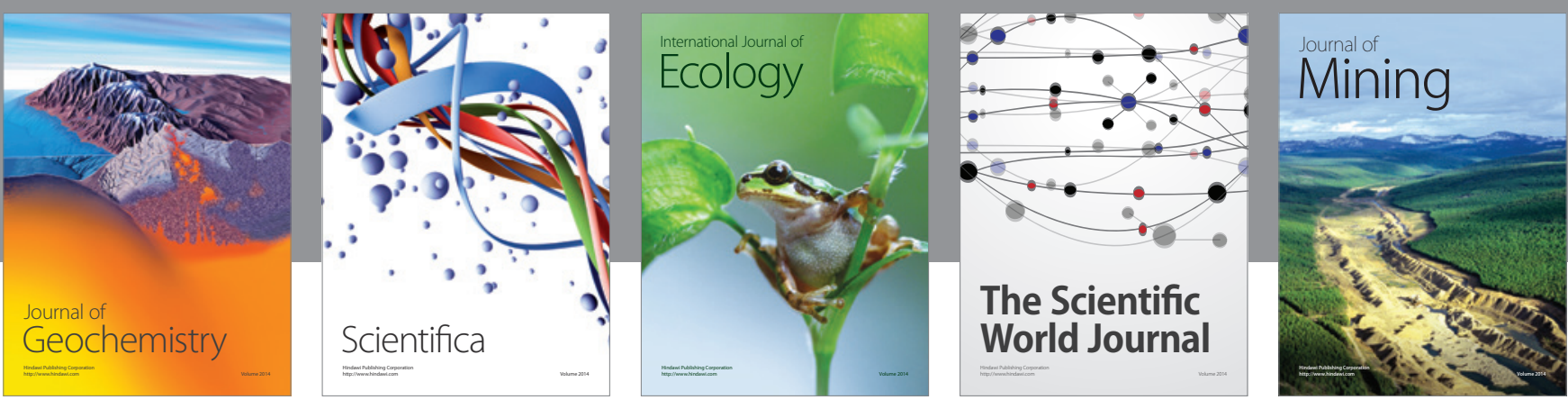

The Scientific World Journal
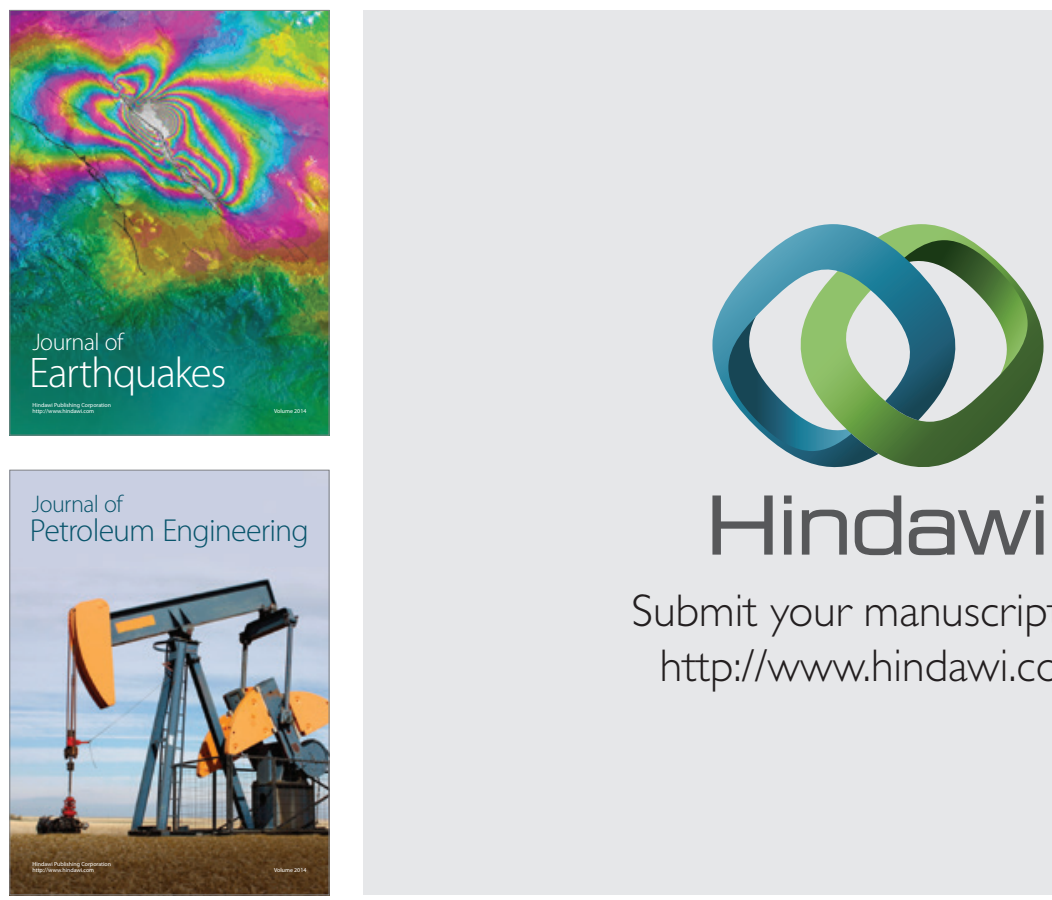

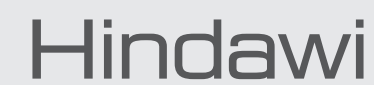

Submit your manuscripts at

http://www.hindawi.com
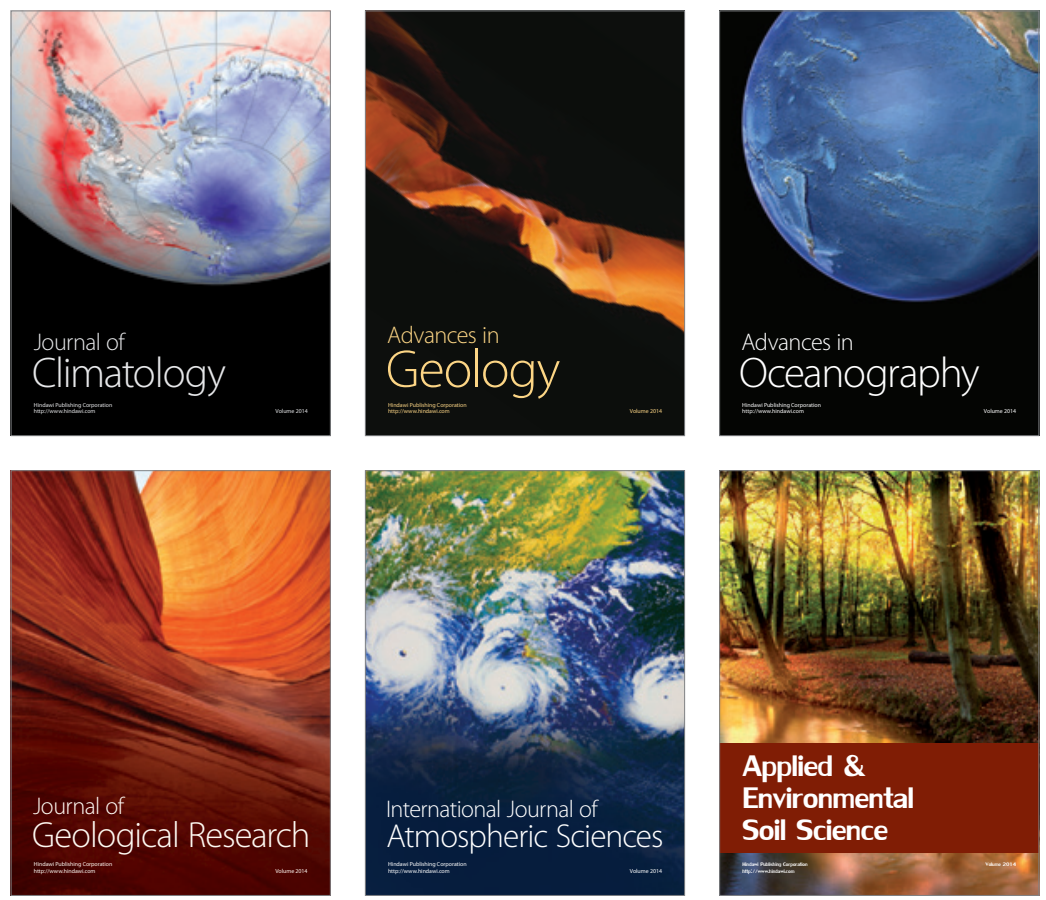
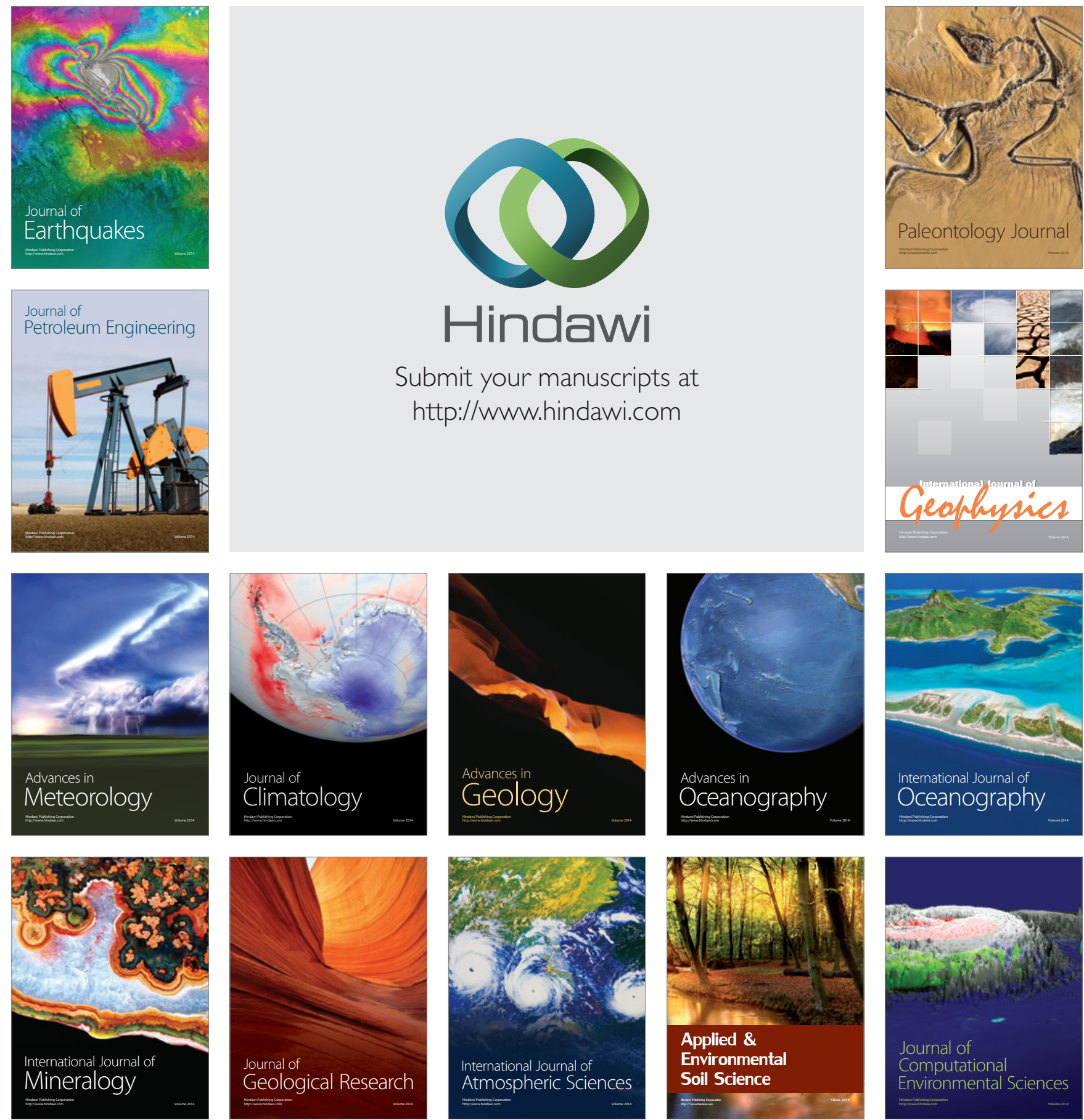